\title{
Habitat suitability models of mountain ungulates: identifying potential areas for conservation
}

Prakash Kumar Paudel ${ }^{1,2,4^{*}}$, Martin Hais ${ }^{2}$ and Pavel Kindlmann ${ }^{1,3}$

\begin{abstract}
Background: Determining the distribution of species and of suitable habitats is a fundamental part of conservation planning. We used slope and ruggedness of the terrain, forest type and distance to the nearest village to construct habitat suitability maps for three mountain ungulates (barking deer (Muntiacus muntjak), Himalayan goral (Naemorhedus goral) and Himalayan serow (Capricornis thar)) in the midhills of western Nepal. We used locations of sightings and signs of presence of these mountain ungulates collected during surveys along transect to derive a suitability value for each variable using Jacob's index. A multiplication approach was used to combine environmental variables and produce a habitat suitability map for each of the three species. An independent dataset was used to evaluate the maps using Boyce's index. This approach provides an overview of the probable distributions of the species in question.

Results: We predict that of the total area studied, $57 \%$ is suitable for M. muntjak, $67 \%$ for N. goral and $41 \%$ for C. thar. Although there are suitable habitats for all three species throughout the study area, the availability of high-quality habitats for these species varied considerably.

Conclusions: Suitable habitats for N. goral and C. thar were fragmented and mostly confined to the southern and northern parts of the study area. This study provides important baseline information for conservation biologists concerned with maintaining biodiversity in the midhills of Nepal.
\end{abstract}

Keywords: Capricornis thar; Habitat model; Midhills; Muntiacus muntjak; Naemorhedus goral; Nepal

\section{Background}

Human interference in the last remaining wilderness areas has resulted in a drastic decline in population size and distribution range of many species of wildlife (Mills 2009; Paudel and Kindlmann 2012a; Morrison et al. 2012). However, actions aimed to minimize this effect are often launched too late, usually after species and their habitats have already been seriously affected (Mittermeier et al. 1998; Myers et al. 2000; Brooks et al. 2002). Hence, it is important to maintain critical wildlife habitats (Poiani et al. 2000; Sala et al. 2000) and establish what determines the present distribution of species, which is especially difficult in mountainous areas and when species population density is low (Gibson et al. 2004). Generally, large-scale

\footnotetext{
* Correspondence: pk.paudel@gmail.com

'Department of Biodiversity Research, Global Change Research Centre AS CR, Bělidla 4a, 60300 Brno, Czech Republic

${ }^{2}$ Faculty of Sciences, University of South Bohemia, Branišovská 31, 37005

České Budějovice, Czech Republic

Full list of author information is available at the end of the article
}

species distribution maps based on small-scale specieshabitat association data were developed with the aid of Geographical Information Systems (GIS) (Osborne et al. 2001; Boitani et al. 2007). Such maps provide an important baseline for designing reserves (Abbitt et al. 2000; Ferrier 2002), species reintroduction (Pearce and Lindenmayer 1998) and rare species assessment (Engler et al. 2004).

The midhills in Nepal are an intermediary landscape between low-lying Tarai in the south and Himalayan region in the north. This region harbours the highest species diversity in the country (Paudel et al. 2012; Primack et al. 2013). However, ecosystems in the midhills were poorly studied in the past; therefore, there is almost no information on their biodiversity and consequently they are very poorly represented in the protected area network (Hunter and Yonzon 1993; Paudel et al. 2012; Paudel and Heinen 2015). The midhills are densely populated and the forest areas there are highly fragmented due to human exploitation for firewood, fodder and 
timber including agricultural lands (Paudel and Šipoš 2014). Subsistence hunting, detrimental to wildlife, is also widespread here (Jackson 1979; Paudel 2012; Paudel and Kindlmann 2012a). Such activities in fragmented forests adversely affect the community structure of wildlife (Andrén 1994; Peres 2001; Fahrig 2003; Paudel and Kindlmann 2012a). For example, Himalayan tahr (Hemitragus jemlahicus), which was once common in the midhills of Nepal, is now extinct there because of habitat loss and hunting (Green 1979), and Himalayan serow (Capricornis thar) is confined to remote forest areas on the slopes of mountains (Wegge and Oli 1997; Paudel and Kindlmann 2012b). The same is true for many other wildlife species living in the midhills. Because of the remoteness and inaccessibility, the distributions of most species in this region are unknown.

Two broad approaches - (1) expert opinion integrated into GIS and (2) mathematical and machine learning algorithms (e.g. tree-based classification, neural networks and random forest, ecological niche factor analysis) - are used to produce habitat suitability maps (Pearce and Ferrier 2000; Guisan and Zimmermann 2000; Store and Kangas Store and Kangas 2001; Breiman 2001; Yamada et al. 2003). Expert opinion has been used with GIS modelling techniques to provide a basis for developing habitat suitability model when adequate empirical data are not available (Store and Kangas Store and Kangas 2001; Yamada et al. 2003; see details in Thuiller and Münkemüller 2010). There is some uncertainty regarding the reliability of such methods mainly because of potential errors in the expert judgments (Maddock and Samways 2000). Similarly, it is possible to use robust statistical approaches to produce habitat suitability maps (e.g. MADIFA, ENFA and BIOMOD) (Guisan and Zimmermann 2000; Hirzel et al. 2002; Rushton et al. 2004; Thuiller and Münkemüller 2010). Such approaches require advanced statistical and computing knowledge and a large dataset on environment collected using a stratified survey (Austin and Meyers 1996). Prior knowledge of environmental determinants of species distribution is crucial to improve the quality and reliability of predictions (Hirzel and Le Lay 2008). There is therefore a need for an alternative modelling approach that does not require sophisticated tools and can be implemented using limited environmental data based on documented species-habitat associations (Gavashelishvili and Lukarevskiy 2008). A multiplicative operation for combining important environmental variables is one of the widely used techniques of model construction (e.g. Liu et al. 2001; Dayton and Fitzgerald 2006).

This study aimed to produce habitat suitability maps for three mountain ungulates, still relatively common in the Nepalese midhills (barking deer (Muntiacus muntjak), Himalayan goral (Naemorhedus goral) and Himalayan serow (Capricornis thar)) and verify their accuracy. All of these ungulates are widely distributed across the Himalayan landscapes, but they exhibit distinct habitat affinities (see the 'Methods' section for details of the species studied). These maps have important applications not only for the conservation of these species, but also because these species serve as indicator species of healthy mountain ecosystem and form a part of the diet of endangered predators in the region: common and clouded leopard at low and snow leopard at high altitudes.

\section{Methods}

\section{Study area}

The study area $\left(81^{\circ} 17^{\prime} 30.216^{\prime \prime}\right.$ to $82^{\circ} 42^{\prime} 58.158^{\prime \prime}$ E, $28^{\circ} 28^{\prime}$ $57.261^{\prime \prime}$ to $\left.29^{\circ} 14^{\prime} 11.418^{\prime \prime} \mathrm{N}\right)$ comprises approximately 2,844 $\mathrm{km}^{2}$ in the midhills of Western Nepal, situated between the Bardia National Park in the lowland Tarai and the Shey Phoksundo National Park in the mountain region (Figure 1).

The habitats vary from dense subtropical deciduous sal forest (Shorea robusta) in the south to alpine pastures in the north. The study area spans over five ecoregions: Himalayan subtropical broadleaf forest, endangered western Himalayan broadleaf forest (Olson et al. 2001), Himalayan subtropical pine forest, western Himalayan subalpine coniferous forest and western Himalayan alpine shrub and meadow (Wikramanayake 2002). The areas below $1,000 \mathrm{~m}$, with a tropical climate, are dominated by sal (Shorea robusta) forest. Areas at altitudes of 1,000 to 2,000 m, with a subtropical climate, are dominated by chir pine (Pinus roxburghii) with an admixture of Quercus incana, Quercus lamellosa, Rhododendron arboreum, Alnus nepalensis etc. Areas at altitudes of 2,000 to 3,000 m, with a temperate climate, are dominated by oak, rhododendron and laurel stands along with conifers such as blue pine, fir and hemlock. In the subalpine zone (3,000 to $4,000 \mathrm{~m})$, several conifers (Pinus wallichiana, Abies spectabilis, Abies pindrow, Tsuga dumosa) and broad-leaved species (Betula utilis, rhododendrons and Quercus semecarpifolia) form diverse types of vegetation (Paudel et al. 2012). In the alpine zone, above $4,000 \mathrm{~m}$, there are some shrubs, but grassland is more common. The region also supports a high faunal (especially mammal) diversity, including $7 \%$ of the mammals endemic to this region (Paudel et al. 2012; Primack et al. 2013). Summer monsoon (June-September) accounts for about $80 \%$ of the precipitation and winter rain is infrequent (Das 1968).

Subsistence agriculture, supporting not much more than the people's basic survival, is the main occupation. Because of rapid population growth and expansion of the road network, human activities are putting an ever increasing pressure on the forests and the species living there (Paudel 2012). 


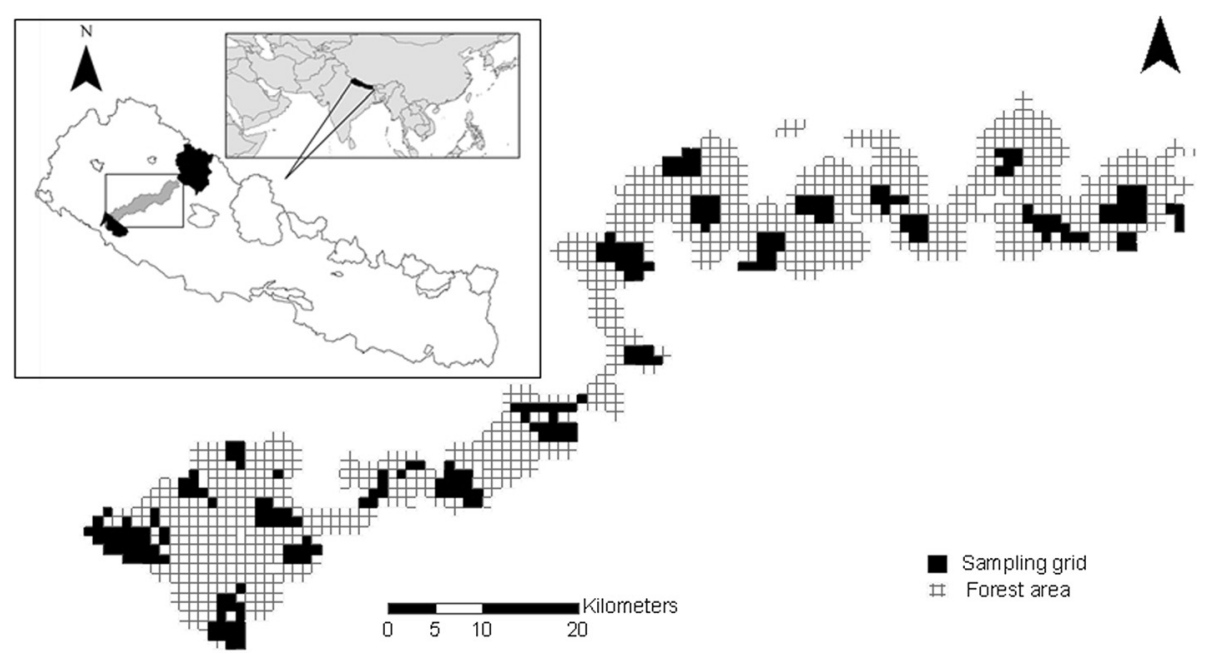

Figure 1 Map of a $1 \mathrm{~km} \times 1 \mathrm{~km}$ grid superimposed over the study area. The black regions are the grids that were sampled. The inset shows a map of the study area (in grey) showing the protected areas Bardia National Park in the south and Shey Phoksundo National Park in the north (in black) of Nepal. Location of the study area in the box (in black).

\section{Species studied}

Barking deer is a relatively small and solitary cervid, which is widely distributed throughout large parts of Southeast Asia (Ohtaishi and Gao 1990; Prater 1990; Roberts 1999). It prefers dense forest with a high understory (Teng et al. 2004; Odden and Wegge 2007) but is also found in degraded forest areas near human settlements (Oka 1998). Because it is territorial, large concentrations of individuals of this species are rarely seen (Odden and Wegge 2007). Barking deer prefers plains and gentle slopes, but such areas have been degraded over the years. Their inability to live in the open and on rugged mountain slopes is limiting them to areas around human settlements (Paudel and Kindlmann 2012a).

Himalayan goral is associated with a wide variety of habitats throughout the mountains (Green 1987; Wegge and Oli 1997). It prefers open plant communities with good grass cover and avoids shrub-rich patches (Cavallini 1992), feeds primarily on grass in all seasons (Mishra and Johnsingh 1996; Fakhar-I-Abbas et al. 2008) and is adapted to steep and rugged mountain terrain (Green 1987; Cavallini 1992; Roberts 1999; Paudel and Kindlmann 2012a). Thus, the steep slope is an important feature preferred by goral (Cavallini 1992; Mishra and Johnsingh 1996; Paudel and Kindlmann 2012a).

Himalayan serow is an IUCN's near threatened (NT) mountain ungulate. It was widely distributed in the mountains of Himalaya (eastern part of the river Jamuna in Bangladesh, northern India, Tibet and Nepal). Now, it is very rare and confined to a few scattered, isolated populations in its former ranges (Green 1987; Grubb 2005) because of habitat loss and hunting (Prater 1990; Paudel and Kindlmann 2012a). In Nepal, the exact distribution of serow is unknown and is restricted to steep forested hills and cliffs, in areas relatively inaccessible to the humans and in protected areas (Wegge and Oli 1997; Paudel and Kindlmann 2012a). Serow inhabits rugged mountains or ridges covered with thick bushes or forests (Nowak and Wilson 1999).

\section{Species distribution data}

We collected presence data for these three mountain ungulates by means of surveys along transects in 21 'clusters' in 2008, 2009 and 2010 (December-June), which were selected as follows: First, we superimposed a $1 \mathrm{~km} \times 1 \mathrm{~km}$ grid on the map of the study area using ArcMap 9.2@ Geographic Information System. Then, we excluded pixels with less than $50 \%$ forest cover, which yielded a set of pixels shown in Figure 1. We generated random points with an 'inhibition distance' (i.e. the smallest distance allowed between any two random placed points) of $5 \mathrm{~km}$. This procedure gave us 24 random points (hereafter 'cluster'). Among them, three points occurred in human habitation and therefore they were excluded. Around each of these 21 clusters, we laid out 10 to 20 transects (depending on its size) at least $100 \mathrm{~m}$ from the edge of a forest. We maintained at least 100-m distance between two transects based on the accessibility and availability of the forests. The transects included riversides and plains, ravines, mountain ridges and steep cliffs.

In each transect, the presence of species was assessed on the basis of the presence or absence of footprints and faeces within a circular plot with a radius of $2.5 \mathrm{~m}$ and by direct sighting at $100-\mathrm{m}$ intervals along the transect, henceforth referred to as 'sampling points'. Two people, mostly local people acquainted with the forests, were 
involved in searching for signs of the presence of the species in question at each sampling point. Since sampling points were relatively small (approximately $20 \mathrm{~m}^{2}$ ), we searched carefully for signs of presence (footprints and faeces), and it is likely that all such signs were detected. If the animal is observed during searching of presence signs, we counted a corresponding sampling point as present. Here, we should be cautious that the absence site could be a pseudo-absence one. This will not affect our results because we are predicting the relative probability of occurrence of the species and the absences are interpreted as unused sites. In order to avoid confusing signs of the presence of livestock (e.g. sheep and goats) with those of wild herbivores, we tested our ability to distinguish footprints and faeces of barking deer, Himalayan goral and Himalayan serow from those of livestock. This test indicated that we were able to distinguish between the signs left by the three ungulates and livestock. Surveys were carried out at 4,328 sampling points along $432.8 \mathrm{~km}$ of transects, which varied in length from 0.3 to $2.5 \mathrm{~km}$ depending on the steepness of the terrain and vegetation. These surveys revealed a total of 687 signs of presence: 229 of barking deer, 316 of Himalayan goral and 142 of Himalayan serow. At each sampling point, we determined (1) vegetation type, elevation and (2) slope (Table 1). Other explanatory data (e.g. distance to the nearest village, topographic ruggedness; see Table 1 for details) were derived from the GIS.

\section{Environmental variables}

Based on documented species-habitat associations (Green 1987; Prater 1990; Cavallini 1992; Mishra and Johnsingh 1996; Wegge and Oli 1997; Roberts 1999; Grubb 2005; Odden and Wegge 2007; Paudel and Kindlmann 2012b; Paudel and Kindlmann 2012a), our field experience and models developed for similar species (Kushwaha et al. 2000), we used various numbers of categories of four main environmental variables (Table 1): We selected environmental variables describing landscape (i.e. slope, topographic ruggedness), habitat type (i.e. vegetation) and human influences (i.e. distance to the nearest village) based on the documented habitat affinities. We tested the performance of these environmental variables for predicting species presence using logistic regressions (Menard 2001). Before performing the regression analyses, we tested for multicollinearity among the data using a Pearson correlation matrix, because environmental variables that are correlated $(r>0.7)$ can bias a model (Berry and Feldman 1985). Nagelkerke $R^{2}$ and receiver operating characteristic curves (ROC) or area under curve (AUC) were used to evaluate the association of the habitat variables with the presence of species. ROC is a plot of true positive cases (or sensitivity) on the $y$-axis against corresponding false positive cases (or specificity) on the $x$-axis for a range of threshold values (Fielding and Bell 1997). It provides a measure of discrimination ability, which varies from 0.5 , when it is no better than expected on the basis of random choice, to 1.0, when it is perfectly discriminatory. Our results indicated that the environmental variables we selected had a high discriminatory ability (Table 2).

We classified environmental variables into a number of classes. Such classes are important when associations between species and environmental variables are nonlinear. Class boundaries here are based on ecological requirement of species in question or types of data:

(i) slope (6 categories, spanning $15^{\circ}$ each: 0 to 15,15 to $30, \ldots, 75$ to 90$)$,

(ii) topographic ruggedness (categorized into four classes using natural breaks based upon Jenks optimization: 0 to $0.05,0.05$ to $0.19,0.19$ to 0.44 and 0.44 to 0.99 - see below for how these values were derived),

(iii) forest type (11 classes of forests and 2 classes of land type: bushy areas and alpine meadow), and

(iv) distance to the nearest village (less than 250, 500, 750 , and $1,000 \mathrm{~m}$ and greater than $1,000 \mathrm{~m}$ )

The environmental data used here were the presence/ absence data, collected in 2008 and 2009 along $325.8 \mathrm{~km}$ of transects $(76 \%$ of total $432.8 \mathrm{~km}$ ) for model development (see below about the model: 'Preparation and evaluation of the suitability map'). This dataset was used to estimate relative probability of usage of the different categories of habitat based on four environmental variables. The remaining presence records, approximately $24 \%$ of the transect data, collected along $102 \mathrm{~km}$ of transects (collected in 2010), were used to evaluate the above model (see 'Preparation and evaluation of the suitability map').

Two Landsat ETM scenes taken on 25 December 2001 (path 143, row 40) and on 21 February 2003 (path 144, row 40), when there was no cloud cover, were obtained from the http://glovis.usgs.gov web pages. Both scenes were geometrically corrected. The data were classified using supervised classification (maximum likelihood Geomatica 2005) based on 146 training areas (polygons), which included 11 vegetation and two land use units (see Table 1). The geographic coordinates of the training areas were determined in the field, using GPS mapping. As some types of vegetation have identical spectra (e.g. grassland vs. alpine meadow; lower temperate broad-leaved forest vs. temperate broad-leaved forest), it was not possible to distinguish between them so they were either aggregated or when possible separated on the basis of altitude (Digital Elevation Model). We separated types of vegetation on the basis of altitude only when they do not overlap 
Table 1 Description of environmental variables used to produce the suitability maps

\begin{tabular}{ll}
\hline Variable & Description \\
\hline Slope & \\
0 to 15 & $\begin{array}{l}\text { Slope of the land surface relative to the horizontal } \\
\text { measured in degrees }\end{array}$ \\
15 to 30 & \\
30 to 45 & \\
45 to 60 & \\
60 to 75 & \\
75 to 90 & \\
Ruggedness &
\end{tabular}

0 to 0.05

0.05 to 0.19

0.19 to 0.44

0.44 to 0.99

Forest type

STSF

SPF

STPBLF

UTCF

RARA

TMF

LTBLF

TBLF

SABLF

SAMF

SACF

BA
Topographic ruggedness measured in terms of the variability in slope and aspect (Sappington et al. 2007)

Subtropical sal forest: north tropical dry deciduous forest (Champion and Seth 1968), sub-tropical hill sal forest (Stainton 1972), hill sal forest (TISC 2002); altitudinal range: 300 to $1,000 \mathrm{~m}$

Subtropical pine forest: chir pine forest (TISC 2002), sub-tropical pine forest (Champion and Seth 1968); altitudinal range: 1,000 to $2,000 \mathrm{~m}$

Subtropical pine broad-leaved forest: chir pine broad-leaved forest (TISC 2002); altitudinal range: 1,000 to $2,000 \mathrm{~m}$

Upper temperate blue pine forest: (TISC 2002); altitudinal range: 2,500 to $3,000 \mathrm{~m}$

Grass and rocky areas: barren hillsides devoid of trees because of rocks, frequently with dense forest nearby; altitudinal range: 300 to 3,200 m

Temperate mixed forest: fir-hemlock-oak forest (TISC 2002), fir-oak-rhododendron forest (TISC 2002), mixed blue pine-oak forest (TISC 2002); altitudinal range: 2,000 to $3,000 \mathrm{~m}$

Lower temperate broad-leaved forest: lower temperate oak forest (TISC 2002), Alnus woods (Stainton 1972); altitudinal range: 2,000 to 2,500 m

Temperate broad-leaved forest: oak-rhododendron forest (TISC 2002), rhododendron forest (TISC 2002), temperate mixed broad-leaved forest (Stainton 1972)

Subalpine broad-leaved forest: birch-rhododendron forest (TISC 2002), subalpine mountain oak forest (TISC 2002), Quercus semecarpifolia forest (Stainton 1972; Champion and Seth 1968); altitudinal range: 3,000 to $4,000 \mathrm{~m}$

Subalpine mixed forest: fir-oak-rhododendron forest (TISC 2002), fir-hemlock-oak forest (TISC 2002); altitudinal range: 3,000 to $4,000 \mathrm{~m}$

Subalpine conifer forest: fir forest (TISC 2002), Abies spectabilis forest (Stainton 1972), Abies pindrow forest (Stainton 1972); altitudinal range: 3,000 to $4,000 \mathrm{~m}$

Bushy area: forest area covered with bushes; altitudinal range: 300 to $4,000 \mathrm{~m}$
Table 1 Description of environmental variables used to produce the suitability maps (Continued)

\begin{tabular}{ll}
\hline AM & Alpine meadow: altitudinal range: $>3,500 \mathrm{~m}$ \\
$\begin{array}{l}\text { Distance to the } \\
\text { nearest village }\end{array}$ & \\
250 & Forest within a $250-\mathrm{m}$ radius of the nearest village \\
500 & Forest within a $500-\mathrm{m}$ radius of the nearest village \\
750 & Forest within a $750-\mathrm{m}$ radius of the nearest village \\
1,000 & Forest within a $1,000-\mathrm{m}$ radius of the nearest village \\
$>1,000$ & Forest outside a $1,000-\mathrm{m}$ radius of the nearest village
\end{tabular}

in their altitudinal ranges. The resulting data were filtered (SIEVE) in order to remove disjointed single pixels. The accuracy of this classification was evaluated using the data (783 points) that were not used in the original classification.

ASTER Global Digital Elevation Model (ASTER GDEM) data were used to derive terrain data. ASTER GDEM data were accessed from http://gdem.ersdac.jspacesystems.or.jp using a map of the study area. The data are available at a resolution of $30 \mathrm{~m}$ per pixel. Topographic ruggedness was calculated using the VRM (vector ruggedness measure) (Sappington et al. 2007) using an ArcGIS script in a $3 \times 3$ window size (http://arcscripts.esri.com/ details.asp?dbid=15423). It is based on a geomorphological method for measuring vector dispersion that is less correlated with slope (Sappington et al. 2007). The dimensionless ruggedness number ranges from 0 (flat) to 1 (most rugged).

Using the land cover map of the study area (Department of Survey), a map of distance to the village was prepared by classifying forest area into five categories based on its proximity to the nearest village (less than $250,500,750$, and $1,000 \mathrm{~m}$ and greater than $1,000 \mathrm{~m}$ ) in ArcGIS. This map was rasterized at a resolution of $30 \mathrm{~m}$.

\section{Preparation and evaluation of the suitability map}

We used approximately $76 \%$ of data (collected along $325.8 \mathrm{~km}$ of transects in 2008 and 2009) for evaluating species-habitat associations (model development) and remaining dataset for model verification. To see specieshabitat associations, we defined the availability $(p)$ for each category of environmental variable as the proportion of all records in all clusters, for which the corresponding value of the environmental variable was 'true' (e.g. in which the slope was between $15^{\circ}$ and $30^{\circ}$ if $p$ for the environmental variable 'slope between $15^{\circ}$ and $30^{\circ}$ ).

For each species and environmental variable, we defined species usage $(r)$ as the proportion of records for which the corresponding value of this environmental variable was 'true' and associated with signs of this species occurrence (e.g. $r$ value for barking deer in areas 
Table 2 Results of binomial logistic regressions of the selected habitat variables

\begin{tabular}{|c|c|c|c|c|c|c|c|c|c|c|c|c|}
\hline \multirow[t]{2}{*}{ Model } & \multicolumn{4}{|c|}{ Barking deer } & \multicolumn{4}{|c|}{ Himalayan goral } & \multicolumn{4}{|c|}{ Himalayan serow } \\
\hline & $\begin{array}{l}\text { Parameter } \\
\text { estimates }\end{array}$ & SE & Wald & $P$ value & $\begin{array}{l}\text { Parameter } \\
\text { estimates }\end{array}$ & SE & Wald & $P$ value & $\begin{array}{l}\text { Parameter } \\
\text { estimates }\end{array}$ & SE & Wald & $P$ value \\
\hline \multicolumn{13}{|l|}{ Topographic variables } \\
\hline Slope & -0.052 & 1.010 & 47.886 & 0.000 & 0.066 & 0.01 & 99.32 & 0.000 & 0.020 & 0.010 & 3.810 & 0.050 \\
\hline Ruggedness & -3.363 & 0.940 & 12.810 & 0.000 & 0.908 & 0.76 & 1.446 & 0.229 & 5.130 & 1.960 & 6.83 & 0.009 \\
\hline Constant & 2.495 & 0.320 & 62.020 & 0.000 & -2.492 & 0.25 & 98.34 & 0 & -1.8 & 0.340 & 31.400 & 0.000 \\
\hline Nagelkerke $R^{2}$ & & 0.335 & & & & 0.411 & & & & 0.331 & & \\
\hline$A \cup C$ & & 0.805 & & & & 0.830 & & & & 0.800 & & \\
\hline Distance to the village & 0.002 & 0.000 & 45.706 & 0.000 & 0.001 & 0.000 & 66.345 & 0.000 & 0.001 & 0.000 & 33.365 & 0.000 \\
\hline Constant & -1.299 & 0.209 & 38.553 & 0.000 & -1.513 & 0.201 & 56.458 & 0.000 & -1.514 & 0.292 & 26.967 & 0.000 \\
\hline Nagelkerke $R^{2}$ & & 0.241 & & & & 0.217 & & & & 0.261 & & \\
\hline$A \cup C$ & & 0.786 & & & & 0.741 & & & & 0.837 & & \\
\hline
\end{tabular}

with a slope between $15^{\circ}$ and $30^{\circ}$ was calculated as the ratio of the number of records of signs of the presence of barking deer divided by the total number of sampling points where the slope was between $15^{\circ}$ and $30^{\circ}$ ).

We then calculated Jacob's index $(D)$ as $D=\frac{r-p}{r+p-2 r p}$ (Jacobs 1974) for each species and each category of environmental variable. The value of $D$ varies from 1 for maximum association to -1 for no association.

For each species and each of the four main environmental variables (slope, topographic ruggedness, forest type and distance to the village), a suitability map was constructed in ArcGIS as follows. Each pixel of the study area was categorized into one of the five classes of habitat suitability according to the $D$ value corresponding to this pixel and of environmental variables and species in question (described in Figure 2 and Table 3). The final $D$ value of all different categories of environmental variables is given in Table 4 .

For each species, the four suitability maps (one for each of the four environmental variables) were multiplied using the map calculator in ArcGIS 9.2 to create a single suitability map for the species (Liu et al. 2001; Dayton and Fitzgerald 2006). This is a better method than a weighted summation because it eliminates optimistic prediction (e.g. 0 suitability in any of the environmental variables gets unsuitable score finally). Furthermore, environmental variable here are already weighted while assigning suitability scores based on Jacob index $(D)$. The map suitability value calculated in this way ranged from 0 (no suitability) to 144 (very high suitability). Finally, we derived four categories (poorly suitable, moderately suitable, suitable and highly suitable) from this continuous scale of 0 to 144 based on the multiplication of three suitability values for each category (e.g. 4 is the value for a highly suitable category of environmental variable. The multiplicative value of the three highly suitable categories is
64. Thus, a pixel with a value greater than 64 was classified as highly suitable in the final map). Thus, we classified each pixel as follows: 0 - unsuitable, 1 to 8 - poorly suitable, 9 to 27 - moderately suitable, 28 to 64 - suitable and greater than 64 - highly suitable. Because we ranked some environmental factors as 0 and used a multiplicative approach, the final map had many areas with a value 0 , indicating that they are unsuitable for the species in question regardless of the suitability of the other environmental variables.

In surveys of large mobile wildlife, absence data are in fact 'pseudo absence', because it is not possible to be certain that the particular location is not used by the target species. We, therefore, used a presence-only data for model evaluation that discriminates a model predicting presence everywhere from a more contrasted model by using predicted-to-expected $(R)$ ratio of each habitat suitability category (Boyce et al. 2002) as $R=P_{i} / E_{i}$, where $P_{i}$ is the proportion of presence records for evaluation points with a habitat suitability class $i$ and $E_{i}$ is the relative area covered by the suitability class $i$. The basic assumption of this evaluation procedure is that a good suitability map should be based on a better evaluation of presence than expected by chance, resulting in $R>1$. Thus, highly suitable habitats should have a proportionally higher number of presence records (Hirzel et al. 2006). We calculated the Boyce index $\left(B_{\mathrm{b}}\right)$ by computing a Spearman rank correlation between $R$ and class rank, which varies between -1 and 1 . Positive values indicate a model, whose predictions are consistent with the distribution of presences in the dataset evaluated, negative values indicate an incorrect model and values close to zero indicate that the model's prediction is not different from random (Boyce et al. 2002; Hirzel et al. 2006). The model evaluation was carried out using an independent dataset of species presences that was collected along $104 \mathrm{~km}$ of transects. It included 52 records of the 


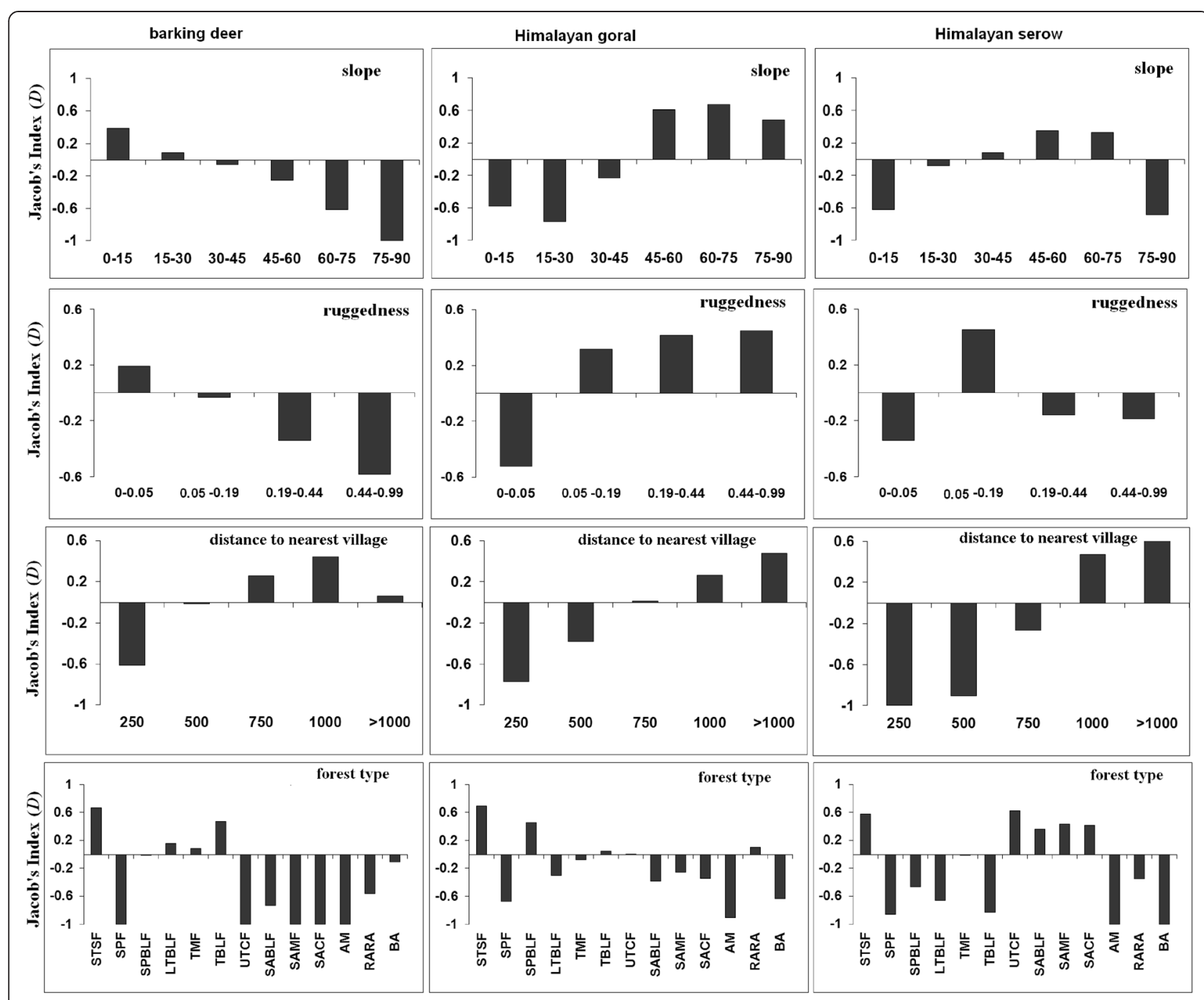

Figure 2 Habitat preferences of each species based on Jacob's index. The first, second and third columns correspond to barking deer, Himalayan goral and Himalayan serow, respectively (see Table 1 for the abbreviations).

presence of barking deer, 63 of Himalayan goral and 38 of Himalayan serow.

We also evaluated whether the observed frequencies of occurrence of the three species in each category of habitat quality were different from those expected based on the availability of habitat categories using a

Table 3 The conversion of Jacob's index $(D)$ into corresponding suitability values

\begin{tabular}{lll}
\hline Jacob's index $(\boldsymbol{D})$ range & Suitability categories & Suitability value \\
\hline-1 & Unsuitable & 0 \\
-1 to -0.5 & Poorly suitable & 1 \\
-0.5 to 0 & Moderately suitable & 2 \\
0 to 0.5 & Suitable & 3 \\
0.5 to 1 & Highly suitable & 4 \\
\hline
\end{tabular}

The lower bound of the class is not included in the corresponding class. chi-square goodness of fit test. Bonferroni confidence interval (adjusted):

$$
p_{i}-z_{(1-\alpha / 2 k)} \sqrt{p_{i}\left(1-p_{i}\right) / n} \leq p_{i} \leq p_{i}+z_{(1-\alpha / 2 k)} \sqrt{p_{i}\left(1-p_{i} / n\right.}
$$

was used to determine, which habitat categories were drivers of significant changes in the model's prediction. Here, $p_{i}$ is the proportion of presence signs in the $i^{\text {th }}$ suitability category, $n$ the sample size (number of recorded presences) and $k$ the number of parameters used in the model.

\section{Results}

Logistic regression revealed the discriminatory power of the habitat variables for indicating the presence of all the species (Table 2). Barking deer was not recorded in areas with a highly rugged and steep terrain and those close to 
Table 4 Suitability rating of the four factors described in Table 3

\begin{tabular}{|c|c|c|c|}
\hline Variable & Barking deer & Himalayan goral & Himalayan serow \\
\hline Slope (degrees) & $\begin{array}{l}\text { Suitable }(<30) \text {, moderately suitable } \\
\text { ( } 30 \text { to } 60) \text {, poorly suitable }(60 \text { to } 75) \text {, } \\
\text { unsuitable }(>75)\end{array}$ & $\begin{array}{l}\text { Highly suitable ( } 45 \text { to } 75) \text {, suitable } \\
(75 \text { to } 90) \text {, moderately suitable } \\
\text { (30 to } 45) \text {, poorly suitable }(<30)\end{array}$ & $\begin{array}{l}\text { Suitable ( } 30 \text { to } 75) \text {, moderately } \\
\text { suitable (15 to } 30) \text {, poorly suitable } \\
\text { (0 to } 15,75 \text { to } 90)\end{array}$ \\
\hline Ruggedness & $\begin{array}{l}\text { Suitable }(<0.05) \text {, moderately suitable } \\
(0.05 \text { to } 0.44) \text {, poorly suitable }(0.44 \\
\text { to } 0.99)\end{array}$ & $\begin{array}{l}\text { Suitable }(>0.05) \text {, poorly suitable } \\
(<0.05)\end{array}$ & $\begin{array}{l}\text { Suitable }(0.05 \text { to } 0.19) \text {, moderately } \\
\text { suitable }(>0.19) \text {, poorly suitable }(<0.05)\end{array}$ \\
\hline $\begin{array}{l}\text { Distance to the nearest } \\
\text { village (metres) }\end{array}$ & $\begin{array}{l}\text { Suitable }(>500) \text {, moderately suitable } \\
\text { (250 to 500), poorly suitable }(>250)\end{array}$ & $\begin{array}{l}\text { Suitable }(>750) \text {, moderately suitable } \\
\text { (250 to 500), poorly suitable }(<250)\end{array}$ & $\begin{array}{l}\text { Highly suitable }(>1,000) \text {, suitable }(750 \\
\text { to } 1,000) \text {, moderately suitable }(500 \text { to } \\
750) \text {, poorly suitable }(250 \text { to } 500) \text {, } \\
\text { unsuitable }(<250)\end{array}$ \\
\hline Forest type & $\begin{array}{l}\text { Highly suitable (STSF), suitable } \\
\text { (LTBLF, TMF, TBLF), moderately } \\
\text { suitable (BA, STPBLF), poorly suitable } \\
\text { (SABLF, RARA), unsuitable (SPF, UTCF, } \\
\text { SAMF, SACF, AM) }\end{array}$ & $\begin{array}{l}\text { Highly suitable (STSF), suitable (SPBLF, } \\
\text { TBLF, UTCF, RARA), moderately suitable } \\
\text { (LTBLF, TMF, SABLF, SAMF, SAMF), } \\
\text { poorly suitable (SPF, AM, BA) }\end{array}$ & $\begin{array}{l}\text { Highly suitable (STSF, UTCF), suitable } \\
\text { (SACF, SAMF, SABLF), poorly suitable } \\
\text { (SABLF, TMF, RARA), unsuitable } \\
\text { (AM, BA) }\end{array}$ \\
\hline
\end{tabular}

human settlements (Figure 2); it occurred mainly in subtropical sal forest, lower temperate broad-leaved forest, temperate mixed forest and temperate broad-leaved forest (Figure 2). Topographic variables were stronger indicators of the presence (Nagelkerke $R^{2} 0.335$, AUC 0.805) than the distance to the nearest village (Nagelkerke $R^{2}$ 0.241, AUC 0.786) for this species. Himalayan goral occurred mainly in subtropical sal forest, subtropical pine broad-leaved forest, temperate broad-leaved forest and rocky and grassy areas (Figure 2). Topographic variables were stronger indicators of the presence (Nagelkerke $R^{2}$ 0.411, AUC 0.830) than distance to the nearest village (Nagelkerke $R^{2} 0.217$, AUC 0.741) for this species (Table 2). Himalayan serow occurred mainly in subtropical sal forest, upper temperate coniferous forest, subalpine coniferous forest and subalpine broadleaved forest (Figure 2). Both topography (Nagelkerke $R^{2}$ 0.331, AUC 0.800) and distance to the nearest village (Nagelkerke $R^{2} 0.261$, AUC 0.837) were important indicators of the presence of this species (Table 2).

The Boyce indices $\left(B_{\mathrm{b}}\right)$ for barking deer and Himalayan goral were at their maximum theoretical limit (1), confirming excellent discrimination (Table 5). The index for Himalayan serow was also high (0.6), which indicates that the model consistently indicates a distribution for goral that accords with its distribution. Predicted-toexpected $(R)$ ratio was also consistently high for the high suitability class and greater than one for the highly suitable habitat for all target species. According to Boyce et al. (2002) and Hirzel et al. (2006) such patterns in suitability maps are consistently close to reality.

Suitable habitat based on all the categories for barking deer covered $57 \%$ of the study area. Of all the suitable habitats for this species, $18 \%, 19 \%, 33 \%$ and 30\% are poorly suitable, moderately suitable, suitable and highly suitable habitats, respectively (Figure 3). Approximately $79 \%$ of the signs of the presence of barking deer occurred in the suitable and highly suitable habitats. The records of barking deer in the predicted habitat categories were disproportionate relative to their availability $\left(\chi^{2}=11.95\right.$, $d f=3, P<0.007)$ as this species was recorded in highly suitable habitats significantly more frequently than expected by chance (Table 6).

Suitable habitat in terms of all the categories for Himalayan goral covered $67 \%$ of the study area. Of all the suitable habitats, $38 \%, 26 \%, 32 \%$ and $4 \%$ were poorly suitable, moderately suitable, suitable and highly suitable habitats, respectively (Figure 4). Approximately 63\% of the signs of the presence of Himalayan goral were recorded in suitable and highly suitable habitats. The records of goral in the predicted habitat categories were disproportionate relative to their availability $\left(\chi^{2}=56.86\right.$, $d f=3, P=0.001)$ as this species was recorded in highly suitable habitats significantly more frequently than expected by chance (Table 6).

Suitable habitats in terms of all the categories covered $41 \%$ of the study area for Himalayan serow. Of all the suitable habitats, $13 \%, 23 \%, 24 \%$ and $40 \%$ were poorly suitable, moderately suitable, suitable and highly suitable habitats, respectively (Figure 5). Approximately 89\% of the records of the presence of Himalayan serow were in suitable and highly suitable habitats. The records of serow in predicted habitat categories were disproportionate relative to their availability $\left(\chi^{2}=10.84, d f=3\right.$, $P=0.012$ ) as significantly fewer than expected were for poorly suitable and moderately suitable habitats and significantly more for suitable and highly suitable habitats (Table 6).

\section{Discussion}

When identifying areas for conservation it is important to know the spatial distribution of good-quality habitat for the target species. We provide landscape-scale maps of the distribution of three mountain ungulates based on 
Table 5 Boyce index $\left(B_{b}\right)$ of the habitat suitability maps for barking deer, Himalayan goral and Himalayan serow

\begin{tabular}{|c|c|c|c|c|c|}
\hline & Suitability (i) & $\begin{array}{l}\text { Proportion of evaluation } \\
\text { points }\left(P_{i}\right)\end{array}$ & $\begin{array}{l}\text { Relative area covered by a } \\
\text { particular suitability class }\left(E_{i}\right)\end{array}$ & $\begin{array}{l}\text { Predicted-to- } \\
\text { expected ratio }\end{array}$ & $\begin{array}{l}\text { Boyce } \\
\text { index }(\mathrm{Bb})\end{array}$ \\
\hline \multirow[t]{4}{*}{ Barking deer } & Poorly suitable & 0.08 & 0.18 & 0.44 & 1.00 \\
\hline & Moderately suitable & 0.13 & 0.19 & 0.68 & \\
\hline & Suitable & 0.27 & 0.33 & 0.82 & \\
\hline & Highly suitable & 0.52 & 0.31 & 1.68 & \\
\hline \multirow[t]{4}{*}{ Himalayan goral } & Poorly suitable & 0.11 & 0.38 & 0.29 & 1.00 \\
\hline & Moderately suitable & 0.25 & 0.26 & 0.96 & \\
\hline & Suitable & 0.44 & 0.32 & 1.38 & \\
\hline & Highly suitable & 0.19 & 0.04 & 4.75 & \\
\hline \multirow[t]{4}{*}{ Himalayan serow } & Poorly suitable & 0.03 & 0.13 & 0.23 & 0.60 \\
\hline & Moderately suitable & 0.08 & 0.23 & 0.35 & \\
\hline & Suitable & 0.37 & 0.24 & 1.54 & \\
\hline & Highly suitable & 0.53 & 0.40 & 1.33 & \\
\hline
\end{tabular}

High values indicate a high consistency in the evaluation of the datasets, and a value greater than 1 indicates good suitability.

habitat suitability. The Boyce index and predicted-toexpected ratio $(R)$ show that the maps accurately describe the general distribution of suitable habitats and distribution of the target species. These maps reveal that all three ungulates are present significantly more often in highly suitable habitats than expected based on the availability of this habitat. Thus, wildlife mainly occurs in highly suitable habitats, which are sparsely distributed in this region, mainly due to human modification of the landscape, which has greatly reduced the proportion of the habitats in region that are of high quality (Fischer and Lindenmayer 2007).

The map for barking deer shows that there is a large area of suitable habitat available for this species throughout the study area (Figure 3), which is made up of $66 \%$ of suitable and highly suitable habitats. This may be because barking deer is adapted to live in a wide variety of habitats (Ohtaishi and Gao 1990; Prater 1990; Roberts 1999; Paudel and Kindlmann 2012a) including degraded forest near human settlements (Oka 1998; Paudel and Kindlmann 2012a). However, although there is a large area of high-quality habitat for barking deer in the middle region, it needs to be urgently conserved, and poaching there reduced because human activities in non-protected areas are likely to increase in the absence of a conservation program. The suitable habitat for goral is scattered throughout the study area (Figure 4) but occurs mainly in the south (along the boundary of the Bardia National Park) and the north of the region (along mountain ridges). Highly suitable habitat makes up only $4 \%$ of the suitable habitat for Himalayan goral. This indicates that Himalayan goral occurs abundantly in small, highly fragmented and patchily distributed habitats, as previously reported by Hajra (2002), who found that less than 1\% of the area is highly suitable for goral in the Sivalik hills in Uttaranchal,
India. The steep grassy slopes, which are the most preferred habitat of goral (Cavallini 1992; Mishra and Johnsingh 1996; Fakhar-I-Abbas et al. 2008; Paudel and Kindlmann 2012a), are now almost exclusively used for agriculture and settlements. The map for Himalayan serow shows its habitat as patchily distributed in the south (along the boundary of the Bardia National Park) and north (along mountain ridges) of the study area (Figure 5). Suitable habitats of all categories cover only $40 \%$ of the study area, which indicates that the area of high-quality habitats (suitable and highly suitable) is very small for Himalayan serow, even though they comprise a relatively large proportion of all categories of suitable habitats (64\%). Thus, the habitat suitability maps for serow indicate that it is important to increase habitat quality and maintain corridors connecting core habitats in order to ensure the long-term survival of this species.

We provide a simple way to identify high-quality habitat for ungulates in a mountain landscape. This approach primarily results in the production of a map of the spatial distribution of the preferred habitats of the target species. It has several advantages over other methods. Many investigators select habitat variables based on the literature and expert judgment. In our study, we first tested whether habitat variables can be used to predict the presence and absence of species using logistic regression and derived suitability indices for particular habitat variables based on Jacob's index $(D)$. Furthermore, the multiplication approach used to combine habitat variables with suitability results in values of 0 (not suitable) and 1 (poorly suitable) and reduces the incidence of overoptimistic predictions (Dayton and Fitzgerald 2006; Gavashelishvili and Lukarevskiy 2008). Another possible criticism may be that too few variables are included in the model. 


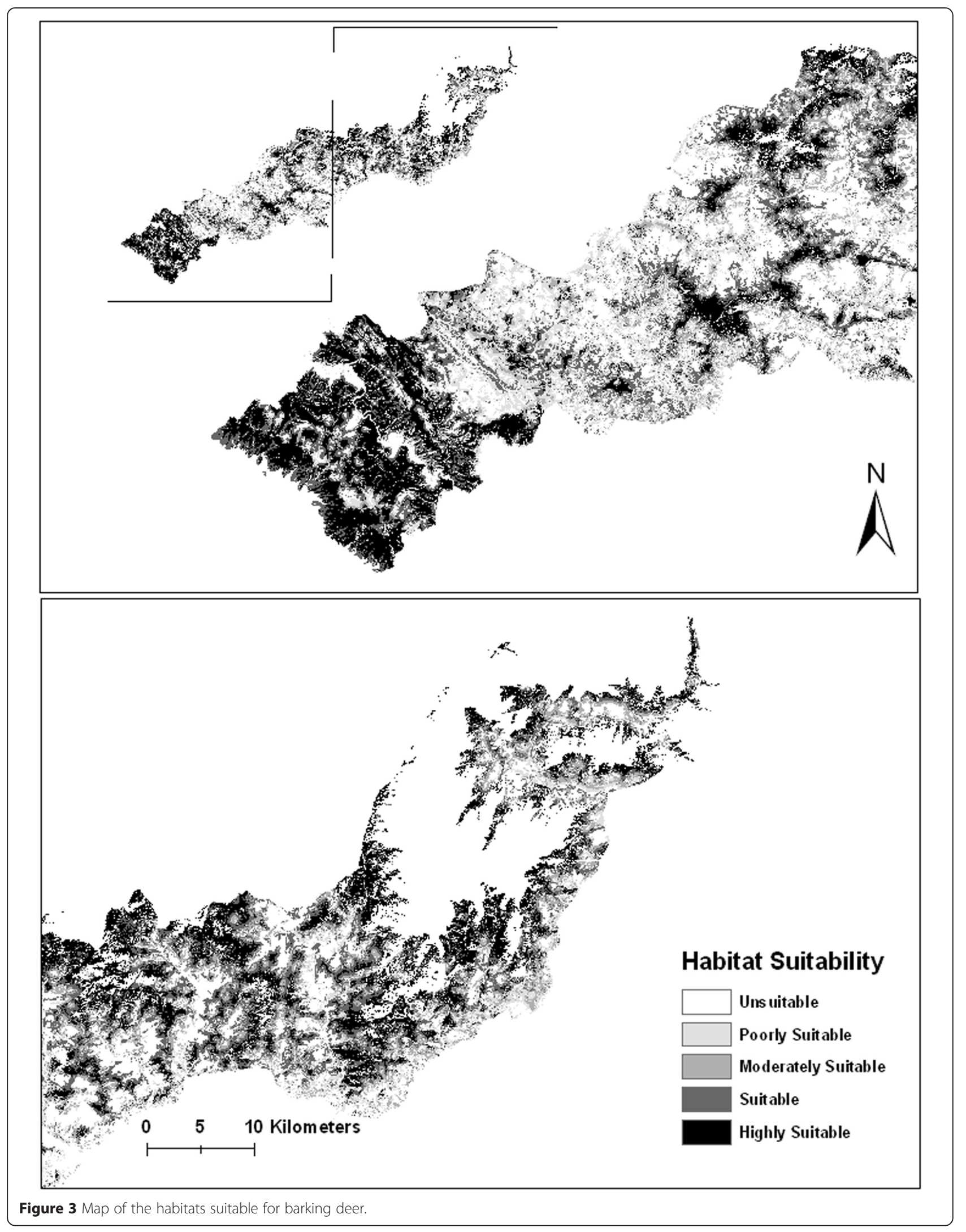


Table 6 Observed and expected occurrence of three species in each of the four habitat categories

\begin{tabular}{|c|c|c|c|c|c|}
\hline & $\begin{array}{l}\text { Predicted } \\
\text { suitability } \\
\text { category }(i)\end{array}$ & $\begin{array}{l}\text { Proportion } \\
\text { of suitable } \\
\text { category }\left(p_{i}\right)\end{array}$ & $\begin{array}{l}\text { Observed frequency } \\
\text { in the ith habitat } \\
\text { category }(0)\end{array}$ & $\begin{array}{l}\text { Expected frequency of } \\
\text { species observation in the } \\
\text { ith habitat category }\left(p_{i} \mathrm{O}+\right)\end{array}$ & $\begin{array}{l}\text { Proportional frequency } \\
\text { in the habitat category } \\
\left(p_{i} \mathrm{O} / p_{i} \mathrm{O}+\right)\end{array}$ \\
\hline \multirow[t]{4}{*}{ Barking deer } & Poorly suitable & 0.18 & 4 & 9.36 & 0.08 \\
\hline & Moderately suitable & 0.19 & 7 & 9.75 & 0.13 \\
\hline & Suitable & 0.33 & 14 & 16.91 & 0.27 \\
\hline & Highly suitable & 0.31 & 27 & 15.98 & 0.52 \\
\hline \multirow[t]{4}{*}{ Himalayan goral } & Poorly suitable & 0.38 & 7 & 24.11 & 0.11 \\
\hline & Moderately suitable & 0.26 & 16 & 16.43 & 0.25 \\
\hline & Suitable & 0.32 & 28 & 20.19 & 0.44 \\
\hline & Highly suitable ${ }^{a}$ & 0.04 & 12 & 2.27 & 0.19 \\
\hline \multirow[t]{4}{*}{ Himalayan serow } & Poorly suitable ${ }^{a}$ & 0.13 & 1 & 4.89 & 0.03 \\
\hline & Moderately suitable ${ }^{a}$ & 0.23 & 3 & 8.70 & 0.08 \\
\hline & Suitable $^{a}$ & 0.24 & 14 & 9.18 & 0.37 \\
\hline & Highly suitable ${ }^{a}$ & 0.40 & 20 & 15.24 & 0.53 \\
\hline
\end{tabular}

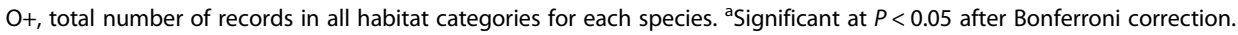

Studies on habitat suitability and distribution of wildlife show that accurate predictions can be made on the basis of a few variables (Liu et al. 2001; Dayton and Fitzgerald 2006; Gavashelishvili and Lukarevskiy 2008).

Biased sampling can result in an erroneous resource selection function. For example, transects that predominately follow a common habitat and topographic feature might not include all the important habitat features for a particular target species. The areas surveyed included significantly representative proportions of the different slopes $\left(r^{2}=0.97\right)$ and topographic ruggedness $\left(r^{2}=0.97\right)$, but not distances to the nearest village $\left(r^{2}=0.78\right)$ and forest type $\left(r^{2}=0.69\right)$. These sampling biases are a result of little sampling within $250 \mathrm{~m}$ of the periphery of villages (beyond $250 \mathrm{~m}$ from villages, $r^{2}=0.98$ ), which are mostly covered by highly degraded forest such as bushy areas and subtropical pine forest (for subtropical pine forest without bushy areas $r^{2}=0.91$ ). These are poor habitats for all species. We argue that biases introduced by not sampling these habitats do not affect the allocation of the suitability index because it is very unlikely that the target species occur in these habitats.

Generally, the prediction of those sites that are occupied is more successful than of those that are not (Osborne et al. 2001). Thus, the maps need to be evaluated in an ecological context (Fielding and Bell 1997). For example, serow locally extirpated from mid-regions although there are large fragments of suitable habitat (Paudel and Kindlmann 2012b). Hence, further research is necessary to determine whether the absence of serow in many suitable habitats is either an effect of small patch size, isolation or human influence or a combination of these factors. We argue that some external factors, such as hunting, might result in the local extinction of certain species. We found that serow in small areas of suitable habitat are more likely to be hunted than those in large areas because small areas are more often monitored by hunting groups (unpublished data). We could not use hunting data in developing the model as such data are difficult to obtain and its spatial precision is uncertain because of the mobile nature of hunting.

Habitat loss and wildlife hunting pose a formidable challenge for wildlife conservation in Nepal's mountains (Jackson 1979; Paudel 2012). Long-term survival of wildlife depends on sufficiently large areas of suitable habitat and opportunities for dispersal between such areas (Harrison 1991; Hanski 1999). Thus, we propose that areas supporting suitable habitats for all three mountain ungulates be designated as conservation areas, especially in areas adjoining the northern boundary of Bardia National Park, along the mountain tops in the middle part and forested areas in the northern part. Except in the national parks (Bardia National Park in the south and Shey Phoksundo National Park in the north), the quantity and quality of habitat is likely to decrease due to human activities such as collecting wood for fuel, harvesting timber and clearing forest for agriculture. Once forests that are easy to access or close to human settlements are exhausted, those in more remote areas at higher altitudes will be exploited. It is therefore important to conserve large patches of habitat and restore connectivity between core areas to ensure species survival. This will enable not only survival of the three target species but also others native to the midhills. The mountain ranges, where suitable habitat for serow and goral exists, in the mid and northern parts of the study area, also provide occasional habitats for a small population of blue sheep (Pseudois nayaur), Himalayan musk deer (Moschus chrysogaster) 


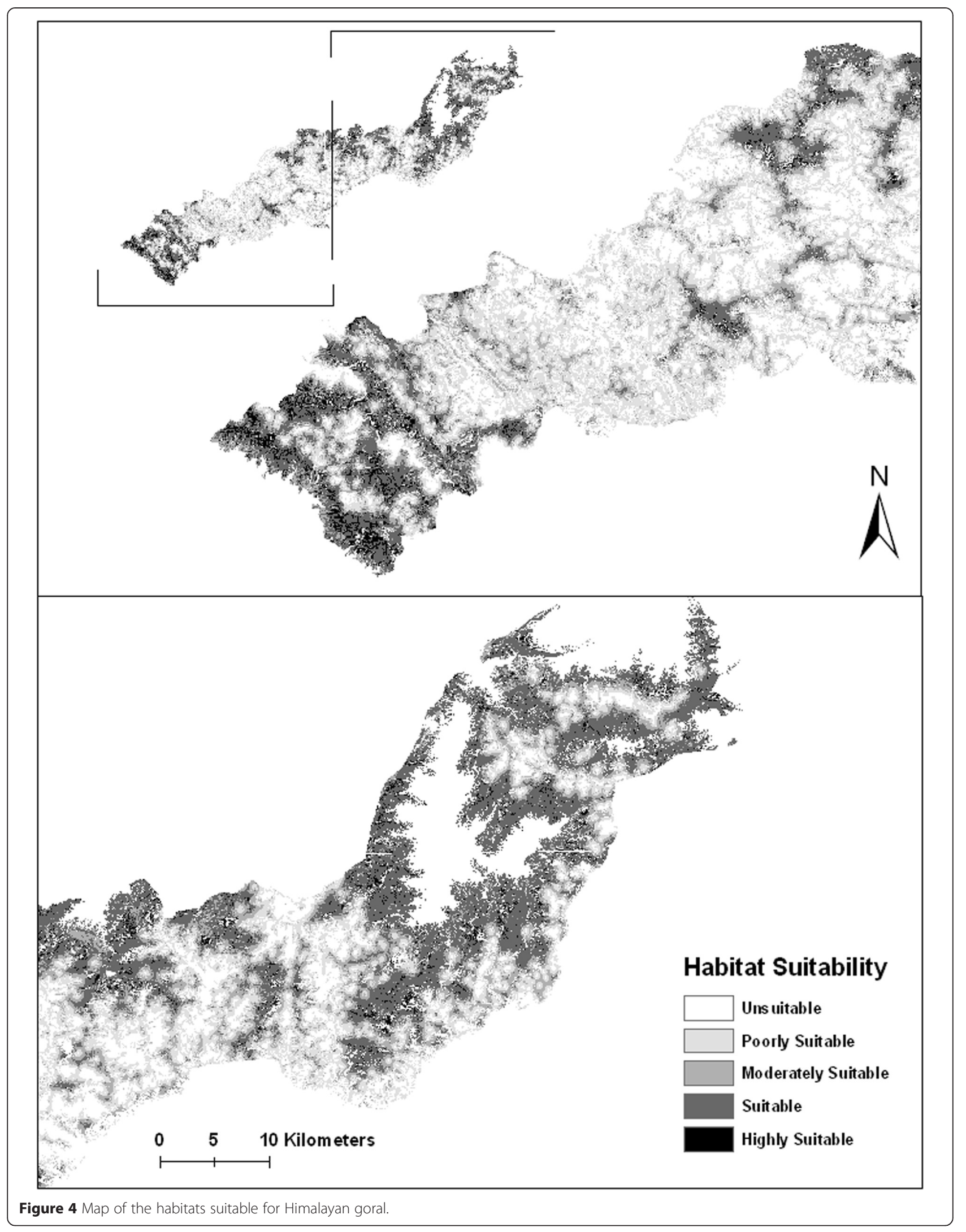




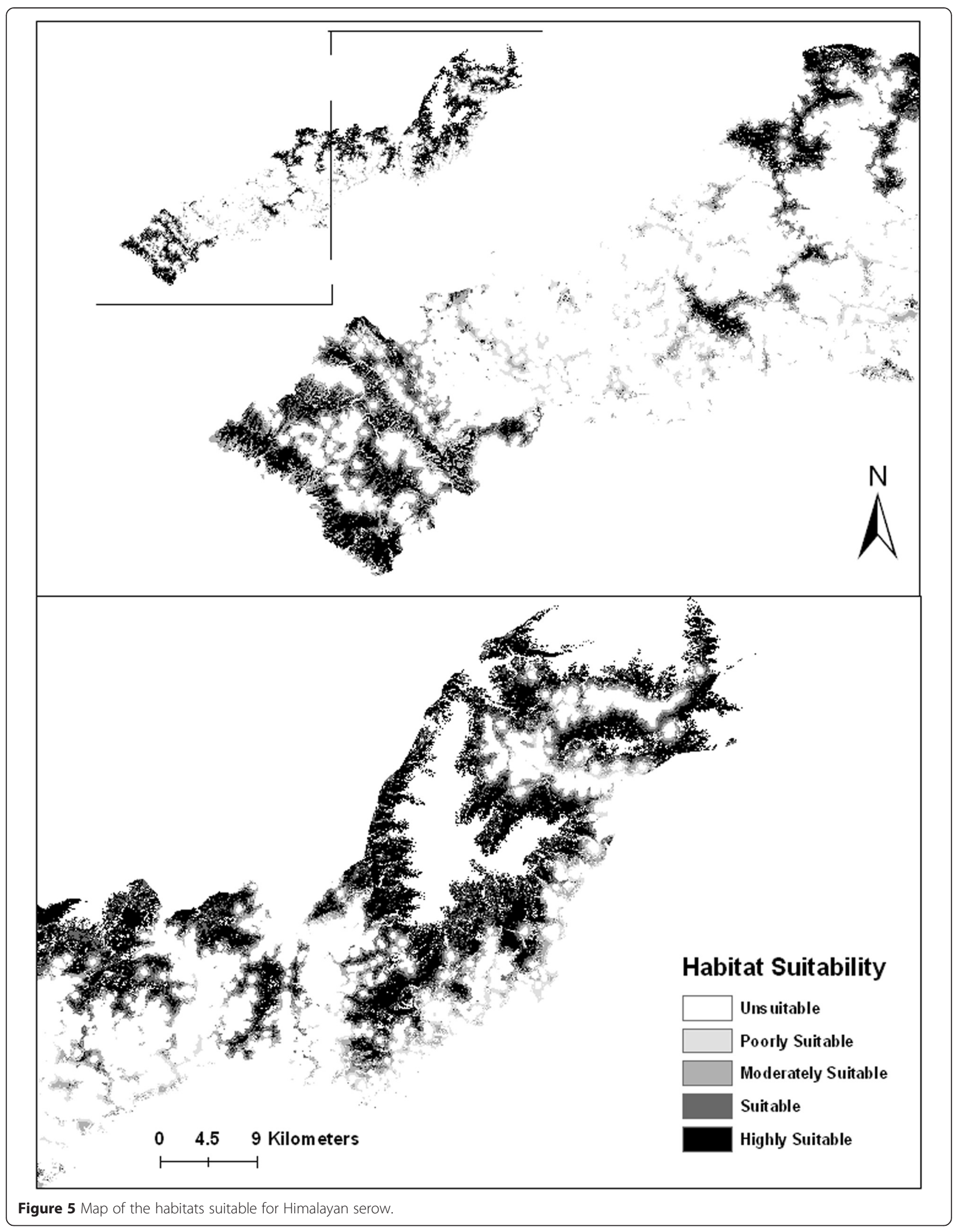


and Himalayan black bear (Ursus thibetanus) (unpublished data). These species are important prey of snow and common leopards (Prater 1990; Roberts 1999). We argue that conservation of core habitats and their connectivity leads to conservation of isolated wildlife populations and their predators such as snow and common leopards because carnivores tend to occur where their preferred prey are abundant (Carbone and Gittleman 2002).

\section{Conclusions}

The habitat suitability maps provide important baseline information for landscape-level conservation over a large altitudinal range in the western midhills of Nepal. The maps show that the majority of the suitable habitats are clustered mostly either in the northern or southern regions of the study area, whereas the mid region harbours small but highly fragmented suitable habitats. The size and spatial configuration of the suitable habitats is critical for the long-term survival of wildlife (Andrén 1994; Hanski 1999; Mech and Hallett 2001). We suggest further studies on connectivity and patch occupancy of wildlife. This is true especially for Himalayan serow that is patchily distributed in isolated habitats. The absence of serow in many large areas of suitable habitat shows the need for the restoration of corridors between such habitats (Paudel and Kindlmann 2012b). Furthermore, the map identifies probable sites for potential reintroduction of serow in areas within its historical range in the midhills of Nepal. Like serow, Himalayan goral is patchily distributed, with high-quality habitats confined to the Churia hills in the southern part of the area, which is a relatively inaccessible area with a rich cover of grass. Therefore, conservation of existing high-quality habitats should be the main focus of the conservation of Himalayan goral.

Here, we use a multi-species approach to identify the problems of conserving wildlife in Nepal. Although the use of surrogate information for certain species is questioned (Bonn and Gaston 2005), but recommended in the absence of other assessment options (Landres et al. 1988), we chose three particular species because they occupy a range of habitats that include those of many other species of wildlife. An extensive survey of the occurrence of carnivores such as leopards (Panthera pardus, Uncia uncia) and Himalayan musk deer in the study area is not possible because they are rare and the topography of the region is highly rugged. Hence, the habitat suitability maps of the species studied can be an effective tool for evaluating their conservation needs and designating areas for conservation.

\section{Competing interests}

The authors declare that they have no competing interests.

\section{Authors' contributions}

PKP conceived and executed the study, collected the field data and performed the modelling analyses. MH carried out the vegetation categorization of the study area using remote sensing. PK helped to draft the manuscript. All authors read and approved the final manuscript.

\section{Acknowledgements}

We thank our field assistants (Mr. Purna Bahadur Bishwakarma, Mr. Sahila Bishwakarma and Mr. Lil B. Khatri) for their tireless support in collecting data. The Department of National Parks and Wildlife Conservation provided permission to do this research. We also thank hundreds of local assistants and people who supported us in many ways to collect data. We thank Tony Dixon for correcting the English. This research was partially supported by the MSMT grant LC06073 and within the National Sustainability Program I (NPU I), grant number L01415 and by grant No. 14-36098G of the GA CR.

\section{Author details}

${ }^{1}$ Department of Biodiversity Research, Global Change Research Centre AS CR, Bělidla 4a, 60300 Brno, Czech Republic. ${ }^{2}$ Faculty of Sciences, University of South Bohemia, Branišovská 31, 37005 České Budějovice, Czech Republic. ${ }^{3}$ Institute for Environmental Studies, Faculty of Natural Sciences, Charles University, Benátská 2, Prague, Czech Republic. ${ }^{4}$ Current address: Center for Conservation Biology, Kathmandu Institute of Applied Sciences, PO Box 23002, Kathmandu, Nepal.

Received: 28 August 2014 Accepted: 1 April 2015

Published online: 25 April 2015

\section{References}

Abbitt RJF, Scott JM, Wilcove DS (2000) The geography of vulnerability: incorporating species geography and human development patterns into conservation planning. Biol Conserv 96:169-175, doi:10.1016/S0006-3207(00)00064-1

Andrén H (1994) Effects of habitat fragmentation on birds and mammals in landscapes with different proportions of suitable habitat: a review. Oikos 71:355-366, doi:10.2307/3545823

Austin MP, Meyers JA (1996) Current approaches to modelling the environmental niche of eucalypts: implication for management of forest biodiversity. For Ecol Manag 85:95-106, doi:10.1016/S0378-1127(96)03753-X

Berry WD, Feldman S (1985) Multiple Regression in Practice. SAGE Publications, Inc., Beverly Hills

Boitani L, Sinibaldi I, Corsi F, Biase AD, Carranza I, Ravagli M, Reggiani G, Rondinini C, Trapanese P (2007) Distribution of medium- to large-sized African mammals based on habitat suitability models. Biodivers Conserv 17:605-621, doi:10.1007/s10531-007-9285-0

Bonn A, Gaston KJ (2005) Capturing biodiversity: selecting priority areas for conservation using different criteria. Biodivers Conserv 14:1083-1100, doi:10.1007/s10531-004-8410-6

Boyce MS, Vernier PR, Nielsen SE, Schmiegelow FKA (2002) Evaluating resource selection functions. Ecol Model 157:281-300, doi:10.1016/S0304-3800(02)00200-4

Breiman L (2001) Random forests. Mach Learn 45:5-32, doi:10.1023/ A:1010933404324

Brooks TM, Mittermeier RA, Mittermeier CG, Da Fonseca GAB, Rylands AB, Konstant WR, Flick P, Pilgrim J, Oldfield S, Magin G, Hilton-Taylor C (2002) Habitat loss and extinction in the hotspots of biodiversity. Conserv Biol 16:909-923, doi:10.1046/j.1523-1739.2002.00530.x

Carbone C, Gittleman JL (2002) A common rule for the scaling of carnivore density. Science 295:2273-2276, doi:10.1126/science.1067994

Cavallini P (1992) Survey of the goral Nemorhaedus goral (Hardwicke) in Himachal Pradesh. J Bombay Nat Hist Soc 89:302-307

Das P (1968) The Monsoons. St. Martin's Press, New York

Dayton GH, Fitzgerald LA (2006) Habitat suitability models for desert amphibians. Biol Conserv 132:40-49, doi:10.1016/j.biocon.2006.03.012

Engler R, Guisan A, Rechsteiner L (2004) An improved approach for predicting the distribution of rare and endangered species from occurrence and pseudo-absence data. J Appl Ecol 41:263-274, doi:10.1111/j.00218901.2004.00881.x

Fahrig L (2003) Effects of habitat fragmentation on biodiversity. Annu Rev Ecol Evol Syst 34:487-515, doi:10.1146/annurev.ecolsys.34.011802.132419

Fakhar-l-Abbas F, Akhtar T, Mian A (2008) Food and feeding preferences of Himalayan gray goral (Naemorhedus goral bedfordi) in Pakistan and Azad Jammu and Kashmir. Zoo Biol 27:371-380, doi:10.1002/zoo.20202 
Ferrier S (2002) Mapping spatial pattern in biodiversity for regional conservation planning: where to from here? Syst Biol 51:331-363, doi:10.1080/ 10635150252899806

Fielding AH, Bell JF (1997) A review of methods for the assessment of prediction errors in conservation presence/absence models. Environ Conserv 24:38-49

Fischer J, Lindenmayer DB (2007) Landscape modification and habitat fragmentation: a synthesis. Glob Ecol Biogeogr 16:265-280, doi:10.1111/ j.1466-8238.2007.00287.x

Gavashelishvili A, Lukarevskiy V (2008) Modelling the habitat requirements of leopard Panthera pardus in west and central Asia. J Appl Ecol 45:579-588, doi:10.1111/j.1365-2664.2007.01432.x

Geomatica (2005) Geomatica 10, Focus user guide. Geomatics Enterprises, Ontario

Gibson LA, Wilson BA, Cahill DM, Hill J (2004) Modelling habitat suitability of the swamp antechinus (Antechinus minimus maritimus) in the coastal heathlands of southern Victoria, Australia. Biol Conserv 117:143-150, doi:10.1016/S0006-3207(03)00288-X

Green MJB (1979) Tahr in a Nepal National Park. Oryx 15:140-144, doi:10.1017/ S0030605300024224

Green MJB (1987) Ecological separation in Himalayan ungulates. J Zool 1:693-719, doi:10.1111/j.1096-3642.1987.tb00751.x

Grubb P (2005) Artiodactyla. In: Wilson DE, Reeder DAM (eds) Mammal Species of the World: A Taxonomic and Geographic Reference, 2-volume set, 3rd edn. Johns Hopkins University Press, Baltimore, pp 637-722

Guisan A, Zimmermann NE (2000) Predictive habitat distribution models in ecology. Ecol Model 135:147-186, doi:10.1016/\$0304-3800(00)00354-9

Hajra A (2002) An ecological study of the vegetation and wildlife habitats in and around Rajaji-Corbett corridor area. PhD thesis, Wildlife Institute of India

Hanski I (1999) Habitat connectivity, habitat continuity, and metapopulations in dynamic landscapes. 87:209-219. doi:10.2307/3546736

Harrison S (1991) Local extinction in a metapopulation context: an empirical evaluation. Biol J Linn Soc 42:73-88, doi:10.1111/j.1095-8312.1991.tb00552.x

Hirzel AH, Le Lay G (2008) Habitat suitability modelling and niche theory. J Appl Ecol 45:1372-1381, doi:10.1111/j.1365-2664.2008.01524.x

Hirzel AH, Hausser J, Chessel D, Perrin N (2002) Ecological-niche factor analysis: how to compute habitat-suitability maps without absence data? Ecology 83:2027-2036, doi:10.1890/0012-9658(2002)083[2027:ENFAHT]2.0.CO;2

Hirzel AH, Le Lay G, Helfer V, Randin C, Guisan A (2006) Evaluating the ability of habitat suitability models to predict species presences. Ecol Model 199:142-152, doi:10.1016/j.ecolmodel.2006.05.017

Hunter ML Jr, Yonzon P (1993) Altitudinal distributions of birds, mammals, people, forests, and parks in Nepal. Conserv Biol 7:420-423

Jackson R (1979) Aboriginal hunting in West Nepal with reference to musk deer Moschus moschiferus moschiferus and snow leopard Panthera uncia. Biol Conserv 16:63-72, doi:10.1016/0006-3207(79)90008-9

Jacobs J (1974) Quantitative measurement of food selection: a modification of the forage ratio and Ivlev's electivity index. Oecologia 14:413-417

Kushwaha SPS, Munkhtuya S, Roy PS (2000) Geospatial modelling for goral habitat evaluation. J Indian Soc Remote Sens 28:293-303, doi:10.1007/ BF02990819

Landres PB, Verner J, Thomas JW (1988) Ecological uses of vertebrate indicator species: a critique. Conserv Biol 2:316-328, doi:10.1111/j.1523-1739.1988.tb00195.x

Liu J, Linderman M, Ouyang Z, An L, Yang J, Zhang H (2001) Ecological degradation in protected areas: the case of Wolong Nature Reserve for giant pandas. Science 292:98-101, doi:10.1126/science.1058104

Maddock AH, Samways MJ (2000) Planning for biodiversity conservation based on the knowledge of biologists. Biodivers Conserv 9:1153-1169, doi:10.1023/ A:1008992602151

Mech SG, Hallett JG (2001) Evaluating the effectiveness of corridors: a genetic approach. Conserv Biol 15:467-474

Menard S (2001) Applied Logistic Regression Analysis, 2nd edn. SAGE Publications, Inc., Thousand Oaks, CA

Mills LS (2009) Conservation of wildlife populations: demography, genetics and management. John Wiley \& Sons

Mishra C, Johnsingh AJT (1996) On habitat selection by the goral Nemorhaedus goral bedfordi (Bovidae, Artiodactyla). J Zool 240:573-580, doi:10.1111/j.14697998.1996.tb05307.x

Mittermeier RA, Myers N, Thomsen JB, Da Fonseca GAB, Olivieri S (1998) Biodiversity hotspots and major tropical wilderness areas: approaches to setting conservation priorities. Conserv Biol 12:516-520, doi:10.1046/j.15231739.1998.012003516.x
Morrison ML, Marcot B, Mannan W (2012) Wildlife-Habitat Relationships: Concepts and Applications. Island Press, Washington

Myers N, Mittermeier RA, Mittermeier CG, da Fonseca GAB, Kent J (2000) Biodiversity hotspots for conservation priorities. Nature 403:853-858, doi:10.1038/35002501

Nowak RM, Wilson DE (1999) Walker's Mammals of the World, 6th edn. Johns Hopkins University Press, Baltimore

Odden M, Wegge $P$ (2007) Predicting spacing behavior and mating systems of solitary cervids: a study of hog deer and Indian muntjac. Zoology 110:261-270, doi:10.1016/j.zool.2007.03.003

Ohtaishi N, Gao Y (1990) A review of the distribution of all species of deer (Tragulidae, Moschidae and Cervidae) in China. Mammal Rev 20:125-144, doi:10.1111/j.1365-2907.1990.tb00108.x

Oka GM (1998) Factors Affecting the Management of Muntjac Deer (Muntiacus muntjak) in Bali Barat National Park, Phd Thesis. University of Western Sydney, Indonesia

Olson DM, Dinerstein E, Wikramanayake ED, Burgess ND, Powell GVN, Underwood EC, D'amico JA, Itoua I, Strand HE, Morrison JC, Loucks CJ, Allnutt TF, Ricketts TH, Kura Y, Lamoreux JF, Wettengel WW, Hedao P, Kassem KR (2001) Terrestrial ecoregions of the world: a new map of life on earth. A new global map of terrestrial ecoregions provides an innovative tool for conserving biodiversity. Bioscience 51:933-938, doi:10.1641/00063568(2001)051[0933:TEOTWA]2.0.CO:2

Osborne PE, Alonso JC, Bryant RG (2001) Modelling landscape-scale habitat use using GIS and remote sensing: a case study with great bustards. J Appl Ecol 38:458-471

Paudel PK (2012) Challenges to wildlife conservation posed by hunting in non-protected areas north of the Bardia National Park. In: Kindlmann P (ed) Himal. Biodivers. Chang. World. Springer, Netherlands, pp 177-195

Paudel PK, Heinen JT (2015) Conservation planning in the Nepal Himalayas: effectively (re)designing reserves for heterogeneous landscapes. Appl Geogr 56:127-134, doi:10.1016/j.apgeog.2014.11.018

Paudel PK, Kindlmann P (2012a) Human disturbance is a major determinant of wildlife distribution in Himalayan midhill landscapes of Nepal. Anim Conserv 15:283-293, doi:10.1111/j.1469-1795.2011.00514.x

Paudel PK, Kindlmann P (2012b) Distribution pattern of the threatened Himalayan serow (Capricornis thar) in western midhills of Nepal: an insight for conservation along an altitudinal gradient. J Nat Conserv 20:177-180, doi:10.1016/j.jnc.2012.01.004

Paudel PK, Šipoš J (2014) Conservation status affects elevational gradient in bird diversity in the Himalaya: a new perspective. Glob Ecol Conserv 2:338-348, doi:10.1016/j.gecco.2014.10.012

Paudel PK, Bhattarai BP, Kindlmann P (2012) An overview of the biodiversity in Nepal. In: Kindlmann P (ed) Himal. Biodivers. Chang. World. Springer, Netherlands, pp 1-40

Pearce J, Ferrier S (2000) Evaluating the predictive performance of habitat models developed using logistic regression. Ecol Model 133:225-245, doi:10.1016/ S0304-3800(00)00322-7

Pearce J, Lindenmayer D (1998) Bioclimatic analysis to enhance reintroduction biology of the endangered helmeted honeyeater (Lichenostomus melanops cassidix) in Southeastern Australia. Restor Ecol 6:238-243, doi:10.1046/j.1526100X.1998.00636x

Peres CA (2001) Synergistic effects of subsistence hunting and habitat fragmentation on Amazonian forest vertebrates. Conserv Biol 15:1490-1505, doi:10.1046/j.1523-1739.2001.01089.x

Poiani KA, Richter BD, Anderson MG, Richter HE (2000) Biodiversity conservation at multiple scales: functional sites, landscapes, and networks. Bioscience 50:133-146, doi:10.1641/0006-3568(2000)050[0133:BCAMSF]2.3.CO;2

Prater SH (1990) The Book of Indian Animals, 3rd edn. OUP, India

Primack RB, Paudel PK, Bhattarai BP (2013) Conservation Biology: A Primer for Nepal. Dreamland Publication, Kathmandu, Nepal

Roberts TJ (1999) Mammals of Pakistan, 2nd edn. OUP Pakistan, Karachi

Rushton SP, Ormerod SJ, Kerby G (2004) New paradigms for modelling species distributions? J Appl Ecol 41:193-200, doi:10.1111/j.00218901.2004.00903.x

Sala OE, Chapin FS 3rd, Armesto JJ, Berlow E, Bloomfield J, Dirzo R, Huber-Sanwald E, Huenneke LF, Jackson RB, Kinzig A, Leemans R, Lodge DM, Mooney HA, Oesterheld M, Poff NL, Sykes MT, Walker BH, Walker M, Wall DH (2000) Global biodiversity scenarios for the year 2100. Science 287:1770-1774, doi:10.1126/science.287.5459.1770 
Sappington JM, Longshore KM, Thompson DB (2007) Quantifying landscape ruggedness for animal habitat analysis: a case study using bighorn sheep in the Mojave Desert. J Wildl Manag 71:1419-1426, doi:10.2193/2005-723

Store R, Kangas J (2001) Integrating spatial multi-criteria evaluation and expert knowledge for GIS-based habitat suitability modelling. Landsc Urban Plan 55:79-93, doi:10.1016/S0169-2046(01)00120-7

Teng L, Liu Z, Song Y-L, Zeng Z (2004) Forage and bed sites characteristics of Indian muntjac (Muntiacus muntjak) in Hainan Island, China. Ecol Res 19:675-681, doi:10.1111/j.1440-1703.2004.00683.x

Thuiller W, Münkemüller T (2010) Habitat suitability modeling. In: Fielder W, Berthold P, Moeller AP (eds) Effects of Climate Change on Birds. Oxford University Press, Oxford, pp 77-85

Wegge P, Oli M (1997) Nepal. In: Shackleton DM (ed) Wild sheep and goat and their relatives: status survey and conservation action plan for caprice. IUCN, Gland, pp 231-239

Wikramanayake ED (2002) Terrestrial ecoregions of the Indo-Pacific: a conservation assessment. Island Press

Yamada K, Elith J, McCarthy M, Zerger A (2003) Eliciting and integrating expert knowledge for wildlife habitat modelling. Ecol Model 165:251-264, doi:10.1016/S0304-3800(03)00077-2

\section{Submit your manuscript to a SpringerOpen ${ }^{\circ}$} journal and benefit from:

- Convenient online submission

- Rigorous peer review

- Immediate publication on acceptance

- Open access: articles freely available online

- High visibility within the field

- Retaining the copyright to your article

Submit your next manuscript at $>$ springeropen.com 